\title{
The spectre of uncertainty in management of exploited fish stocks: The illustrative case of Atlantic bluefin tuna
}

\author{
Jean-Marc Fromentin $^{\mathrm{a}, *}$, Sylvain Bonhommeau ${ }^{\mathrm{a}}$, Haritz Arrizabalaga ${ }^{\mathrm{b}}$, Laurence T. Kell ${ }^{\mathrm{c}}$
}

\footnotetext{
${ }^{1}$ Ifremer (Institut français de recherche pour l'exploitation de la mer), UMR 212 EME, boulevard Jean Monnet, BP 171, 34203 Sète Cedex, France

${ }^{2}$ AZTI-Tecnalia, Herrera Kaia, Portualdea z/g - 20110 Pasaia (Gipuzkoa), Spain

3 ICCAT (International Commission for the Conservation of Atlantic Tunas) secretariat, Corazón de María 8 , 28002 Madrid, Spain
}

\author{
*: Corresponding author : Jean-Marc Fromentin, tel.: +33 499573232 ; fax: +33 499573295 ; \\ email address : jean.marc.fromentin@ifremer.fr
}

\begin{abstract}
:
The recent overexploitation of East Atlantic and Mediterranean bluefin tuna stock has been well documented in the media where it has become the archetype of overfishing and general mismanagement. Beyond the public debate, the crisis also highlighted how the interactions between science and management can change through time according to the awareness of the public opinion. To reflect these issues, the history of Atlantic bluefin tuna overfishing is first described. Then, the major uncertainties that undermine the current scientific advice are summarized and the importance of reducing their impacts by improving knowledge and developing robust scientific framework is considered. The study also discusses how uncertainty was used by different lobbies to discredit science-based management. The recent improvement in bluefin tuna stock status following the implementation of the rebuilding plan shows that, despite uncertainty in the scientific advice, the management of a heavily exploited fish stock can be positive when there is a political will. However, optimizing long-term yields of modern fisheries implies good science. The study concludes by advocating for the implementation of a scientific quota that should be part of the management framework to support the scientific advice.
\end{abstract}

\section{Highlights}

Description of the history of Atlantic bluefin tuna overfishing. Summary of the major sources of uncertainty in the scientific advice. Uncertainty is inherent in the scientific advice. Public awareness obliged managers to better pay attention to the scientific advice. Successful management of exploited fish stock firstly implies strong political will.

Keywords: Overexploitation ; Rebuilding ; Uncertainty ; Management ; Scientific diagnosis ; Tuna 


\section{An emblematic case of overfishing}

A commercially exploited fish has rarely been given as much media coverage as Atlantic bluefin tuna (ABFT), especially the East Atlantic and Mediterranean stock (ABFTE) that supports the bulk of ABFT catches. During the 2000s, Non-Governmental Organisations (NGOs) publicised ABFTE as the archetype of overfishing and general mis-management of the world fisheries [see e.g. 1]. There are good reasons for this. ABFTE fisheries indeed crystallised most of the problems found in many fisheries, i.e. severe overcapacity, open access in international waters, geographical expansion of the fisheries, high market value and deficient governance at both international and national levels $[2,3$, 4].

ABFTE was traditionally canned or sold to the Mediterranean fresh market and its market value was rather low. However, the rise of the sashimi market (firstly in Japan and then in USA, Europe, Korea and China) led to strong demand for fresh ABFTE, especially since the 1980s [5]. Consequently, the value of ABFTE increased in the following decades and bluefin tuna became, in the media, the fish that was worth its own weight in gold when quoting the New Year auctions on the Tsukiji fish market in Tokyo. Unfortunately, the increasing value of ABFTE induced a sharp increase in the fishing efficiency and capacity of various fleets during the 1990s and 2000s, especially in the Mediterranean Sea. This together with new storage technologies and farming practices introduced in the late 1990s created a severe and uncontrolled overcapacity that in turn led to a critical overexploitation of the resource [6].

The scientific community, especially the scientific body of the International Commission for the Conservation of Atlantic Tunas (ICCAT, the regional fisheries organisation that has in charge to monitor and manage tuna and tuna-like species in the Atlantic ocean) raised serious concern about ABFTE stock status since the early 1990s and estimated the stock to be overexploited in 1996 [7]. From 1998 onwards a Total Allowable Catches (TAC) system, together with size limit regulations and time/area closures, were progressively implemented. Furthermore, from the late 1990s to 2008, 
ICCAT did not follow the advice of its own scientific body and always recommended a TAC that exceeded the scientific recommendations (Fig. 1). This was partly due to the multilateral nature of ICCAT and a decision-making process based on consensus. Conflicts of interests between countries impede strong decision-making, especially to limit catches. In addition, the ABFTE market was highly profitable and economic interests took precedence over conservation based ones [an unfortunate but quite common situation for many exploited fish stocks, even for fish of lower economic value, see 8]. In such a context, uncertainties inherent in any scientific advice were often used by stakeholders and managers to argue for or against different management options (especially TAC). The only way to avoid such a deleterious process would be to agree on management measures (such as TAC) evaluated with respect to agreed objectives, e.g. a harvest control rule developed using Management Strategy Evaluation (MSE). Unfortunately, such a procedure was not in place and needs to be implemented rapidly to avoid any reiteration of such shortcoming in near future (see also below). This has been recognized by ICCAT, which established a working group for enhancing the dialogue between Fisheries Scientists and Managers in 2013 through a process that would develop MSE.

(Fig. 1 about here)

Last but not least, management regulations were ineffective in limiting catches in the Mediterranean Sea (mostly taken in international waters) because of a lack of compliance and control, which was primarily due to a general mismanagement of ICCAT at that time. Therefore, catches by most of the fisheries (often with the approval of their governments) were significantly underreported until 2007, allowing severe overexploitation to occur. This together with illegal fishing under flags of convenience led to considerable Illegal Unreported and Unregulated (IUU) catches from 1998 to 2007 (Fig. 1). Although these IUU were documented by ICCAT Scientific Committee and several NGOs inquiries $[1,9,10]$, ICCAT Commission took little action to curtail them prior to 2008. Consequently, ABFTE catches were probably at or above 50,000 tonnes per year during this decade, while ICCAT 
Scientific Committee recommended a TAC between 15,000 tonnes and 25,000 tonnes in the same period.

Following the pressure from several NGOs, which stressed the inconsistency between scientific advice and management, ICCAT implemented a rebuilding plan in 2007. This plan included more restrictive management regulations, particularly in reducing the length of the fishing season for the main fleets (purse seiners), increasing the minimum size of fish (from $10 \mathrm{~kg}$ to $30 \mathrm{~kg}$ ) and started to establish a real and effective monitoring control and surveillance system. However, two key issues were not tackled and still remained: high catches levels and overcapacity [10]. The plan was reinforced in 2008, including the strengthening of the control measures and a reduction of fishing capacity over 5 years, but again the TAC remained 2 to 3 times higher than scientific advice. The procrastination of ICCAT led in 2009 to the demand by Monaco to list ABFT under Appendix 1 of the Convention of International Trade in Endangered Species of Wild Fauna and Flora (CITES), which was strongly supported by most of the NGOs. ABFE was pointed as an archetypal example of mismanagement by its responsible body (ICCAT) and another international organisation (CITES) was advocated by some parties to improve the situation [11-13]. In 2009, ICCAT fully endorsed the scientific advice and recommended a low TAC for the three following years [at about 13,000 tonnes, see 14]. Undoubtedly, such a result would not have happened without the strong pressure of the NGOs, which succeeded, in a few years, in calling attention to the poor stock status of ABFTE and so obliged ICCAT to take action.

\section{Towards rebuilding}

One of the most spectacular effects of the rebuilding plan since 2010 was the drastic decrease in total catches of ABFTE (Fig. 2). From 1998 to 2007, reported catches were about 30,000 to 35,000 tonnes, but, as mentioned before, ICCAT Scientific Committee estimated that catches were in the order of $50,000 \mathrm{t}$ per year during this period [an estimation based on the number of vessels 
operating in the Mediterranean Sea and their respective catches rates, see 9]. Since 2008, the ICCAT Scientific Committee did not detect any unreported catches using capacity information and concluded that a substantial decrease in the catches (including IUU) occurred following the enforcement of the controls. In 2011 and 2012, reported catches were around 10,000 tonnes, i.e. the lowest catches records since 1950 (i.e. the beginning of the time series on which scientific advice is based) and about 5 times less than 3 years before (Fig; 2).

In contrast to the mid-2000s, all CPUE indices used for the 2012 ABFTE stock assessment displayed positive trends in recent years. Fisheries-independent information from the aerial surveys performed on the juvenile fish in the Northwestern Mediterranean Sea provide similar indications, showing a four-fold increase in juveniles abundance in 2009-2011 compared to 2000-2003 [15]. In contrast to the 2006 and 2008 stock assessments, which detected a rapid and strong decline in the spawning stock biomass (SSB) in the terminal years, the last assessment showed a more optimistic perception of the stock size. The SSB did not exhibit any strong depletion in the mid-2000s and further showed clear signs of increase in recent years in all the runs that have been investigated. Trends in fishing mortality (F) for the younger ages (ages 2-5) and for oldest fish (ages 10+) decreased sharply since the late 2000s, after a 20 years (or more) increase, to reach the lowest historical values. The general trend in $\mathrm{F}$ for the oldest fish is consistent with expert knowledge, especially the shift in targeting towards larger individuals destined for fattening and/or farming during the 1990s (Fig. 2).

\section{(Fig. 2 about here)}

The perception of stock status derived from the 2012 assessment has thus greatly improved relative to past assessments. $F_{2011}$ is noticeably below the reference target level $\left(F_{0.1}\right.$ a proxy for the fishing mortality that would provide the maximum sustainable yield) in all scenarios $\left(0.36<F_{2011} / F_{0.1}<0.7\right)$. If $F_{2011}$ would be consistent with ICCAT Convention Objectives, current biomass is most likely to be below the level expected at $\mathrm{F}_{0.1}$ (i.e. $\mathrm{SSB}_{\mathrm{F} 0.1}$ ), which is not surprising for a long lived species. Note that last SSB value is among the highest values of the time series, which is rather intriguing for a recently 
overfished stock (Fig. 2). There are three main (and non-competitive) explanations to this: (i) past and/or recent SSB estimates are biased due to unquantified uncertainties (see following section), (ii) absolute values of SSB can hardly be compared between each other because $\mathrm{SSB}_{\mathrm{F} 0.1}$ changed considerably over time due to changes in recruitment levels and/or selectivity patterns and (iii) the stock would be under current $\mathrm{SSB}_{\mathrm{F} 0.1}$ since the beginning of the series (i.e. 1950), which is not impossible regarding point (ii) and the heavy exploitation supported by this stock since the Second World War [16].

Projections for a range of TACs are consequently more optimistic than those from the previous assessment and indicated that $\mathrm{ABFTE}$ rebuilding to the $\mathrm{SSB}_{\mathrm{F} 0.1}$ level could be achieved by the end of the rebuilding plan (2022) for catches levels $\leq 26,000$ tonnes. Based on current knowledge and modeling assumptions, ABFTE could thus be rebuilt by 2022 or before if ICCAT continued to control ABFT catches at the current level. However, this implies that current unquantified uncertainties would not affect our perception of stock status and population dynamics, which is clearly unlikely.

\section{Uncertainties in the stock assessment}

While there are a lot of uncertainties in relation to the ABFTE stock assessment, this is not that different from other exploited fish stocks (including data rich ones). Uncertainties in stock assessment arise from three major sources: (i) process errors, i.e., our understanding of ABFTE biology and population dynamics, (ii) observation errors, i.e. the quality/quantity of the data used and (iii) model errors, i.e. the ability of assessment models to correctly reproduce key population dynamics patterns [17].

\subsection{Process errors}


The primary uncertainties about ABFT biology and population dynamics that affect stock assessments are: population structure, natural mortality, age structure, population growth rate (or productivity) and recruitment.

For successful fisheries management, RFMOs should ensure that the assumed stock structure used in the management arena corresponds with the real population structure of the species $[18,19]$. Otherwise, the most productive sub-populations could be exploited at suboptimal levels, and, more importantly, less productive sub-populations could collapse (even at $\mathrm{F}_{\mathrm{MSY}}$ strategy), reducing genetic diversity and resilience of the species to environmental changes [20]. Although ICCAT has managed ABFT as two stocks since the 1980 s, with the boundary between the two spatial units being the $45^{\circ} \mathrm{W}$ meridian, ABFT population structure remains largely unidentified [5]. According to recent genetic studies [21-23] and retrospective analysis [16], ABFT population structure is likely to be more complex than the current two stocks hypothesis, with probably at least two populations within the Mediterranean. If this is confirmed, ICCAT might need to change the current two stock management framework to avoid the risk of eroding the Mediterranean bluefin tuna sub-populations, especially considering the high fishing pressure on Mediterranean ABFT over the last two or three decades. Avoiding genetic erosion is particularly important in the long-term, so as to be able to adapt to changing environmental conditions due to ongoing climate change [24].

Natural mortality $(\mathrm{M})$ is one of the key uncertainties in population dynamics models of exploited fish stocks because $M$ cannot be observed and is difficult to estimate [see 25 for a recent review]. For ABFTE, as for the vast majority of exploited fish stocks, $M$ is fixed and corresponds to the age-specific but time invariant vector estimated from mark-recapture information for the Southern bluefin tuna. This assumption is thus partly arbitrary and different assumptions in M would strongly change our perception of ABFTE stock status because it would translate in a different productivity [26].

Recent recruitment levels and, thus ABFTE productivity, remain highly uncertain because of the stochastic nature of the recruitment dynamics in most bony fish species (see below). In addition, 
ABFTE (as with most marine bony fish) displays no clear stock-recruitment relationship, so that future projections are performed using average past recruitment levels, which is a strong and rather hazardous assumption.

\subsection{Observation errors}

Scientists are apparently fortunate with regards to the quantity of data for ABFTE, as catches data and CPUE indices are available since 1950 [14]. However, the quality of the data is debatable. For instance, the total catches level is unreliable due to important IUU catches from 1996 to 2007. Furthermore, this period is also characterized by the paucity of reliable catch-at-size for several key fisheries because of the rise of farming and the corresponding decrease of landings [27].

In contrast to small pelagic and demersal fish, another recurrent issue for large pelagic fish is the lack of fisheries-independent indices used to calibrate stock assessment models or to directly assess the stocks. This problem has become even more acute for ABFTE, as recent regulatory measures of the rebuilding plan have significantly affected all the CPUE indices. This plan indeed induced extensive changes in the spatial patterns of the fisheries, length of the fishing season and target sizes, which in turn have impaired the ability of CPUE indices to track changes in ABFTE abundance [14]. Large-scale fisheries-independent information and surveys are therefore needed to provide more reliable stock status indicators. The current aerial survey in the NW Mediterranean [15] would be a good basis to do so, but it has, currently, a too restricted spatial coverage.

Because ABFTE is a long lived species, it is assessed using an age based model. Different sources of information (i.e., otolith, spine, vertebra and tagging) have been used to translate length data into age data. However, the catch-at-age (CAA) generated from catch-at-size (CAS) using age slicing contains substantial errors because: (i) the current CAS includes many substitutions due to the lack of basic size data for some major fisheries [28], (ii) growth varies by year and/or cohort and (iii) ABFT growth is asymptotic, so that large individuals may have a wide range of ages. The translation of the 
CAS into the CAA thus introduces important biases for the virtual population model (VPA) that assumes that CAA is exact [i.e. with no observation errors, see 17].

\subsection{Model errors}

Traditional stock assessments mainly consider only uncertainties in observations and process (e.g. recruitment), but uncertainty about the actual dynamics (i.e. model uncertainty) has often a larger impact on achieving management objectives [29]. The current stock assessment is conducted using a statistical VPA [30], an approach that is subject to several biases [18].

As noted above, ageing large fish is difficult, therefore the Scientific Committee assumes a plus-group of 10 years old fish (i.e. grouping all individuals equal to and older than 10 years). Such an assumption implies that all fish > 10 years display, among other things, similar growth, behavior and hence fishing and natural mortality rates, which is not the case. There are other key difficulties with the plus-group, such as it is estimated assuming some relationship with the next age [28]. Sensitivity analyses have shown that assuming a different plus-group (e.g. fish $>12,14$ or 16 years) and/or modifying the specification to next age considerably change both the absolute levels of SSB and its trend [28]. Ageing and plus-group assumptions are specific technical issues, but they are amongst the most influential ones in the current ABFTE stock assessment.

The above uncertainties mean that many different VPA specifications are possible. Therefore, the Scientific Committee ran different ad-hoc scenarios reflecting assumptions about different parameters and different sets of data. In the last stock assessment, the speed and the magnitude of the upward SSB trend varied considerably between runs, indicating that the perception of the stock status strongly depends on the model specifications [14].

Estimates of current stock status relative to MSY benchmarks (here $F_{0.1}$ ) are highly sensitive to the assumptions about mortality-at-age and hence selectivity patterns [31] as well as to technical assumptions made in the VPA. Biomass reference points are further strongly impacted by the 
hypotheses made about recruitment levels. The estimates of the selectivity patterns in the 2010 and 2012 ABFTE stock assessments significantly affected the benchmarks. The estimate of MSY in 2012 was lower than that made in 2010 because of a slight shift from fish of large to medium size classes. Consequently, the more optimistic perception of the stock status in 2012 was not only due to the rebuilding of the population, but also to a decrease of MSY. In other words, the perception of the stock (i.e. $B_{\text {current }} / B_{M S Y}$ ) has also increased because $B_{M S Y}$ has decreased. The selection pattern also impacts on the population growth rate, for example if fishing mortality of the plus-group is reduced then the stock biomass maybe expected to rebuild faster. Changes in the estimates of selection pattern mean that the reference points and potential recovery rate of a population estimated in a given stock assessment session (or a year) will be different from those estimated in another session (year). This is problematic when assessing the performances of a given rebuilding plan: against which reference points should the exploited population be evaluated: the ones in which the plan was based or the latest estimates? This classical and key problem in fisheries science has not received, to our knowledge, any satisfactory solution, but it deserves special attention. This is especially true for overfished/depleted stocks because rebuilding plans often (if not always) imply considerable changes in selectivity patterns. For ABFTE, the fraction of the catches in number of juvenile fish could exceed $80 \%$ in some years before the rebuilding plan while it is now below $20 \%$.

Projections are known to be a problematic area in stock assessments [32]. For ABFTE, the Scientific Committee ran different ad-hoc scenarios to account for different plausible levels of productivity (which were all based on past estimates) or future selectivity patterns. However, the results of the projections were impaired by sources of uncertainties that cannot be quantified based on our current knowledge, especially uncertainties about population structure, population dynamics (such as natural mortality), levels of IUU catches and, even more importantly, future recruitment levels. Therefore, the results of the projection must be interpreted with great care. This is especially true when the results are given by levels of probabilities against different levels of catches [i.e. the socalled Kobé II matrix, see 33], which often give the feeling to the managers that all sources of 
uncertainties have been quantified and the sources considered have all equal weight, which is far from the truth. For these reasons, the ICCAT Scientific Committee has little confidence in the outputs of the projections and recommended maintaining a low TAC (i.e. in the range of the 2010-2012 values) for the coming years.

\subsection{Decreasing uncertainties}

Decreasing uncertainties should result in a reduction in risk (i.e. the probability of something bad happening) and improved yield [34]. In the medium-term, a significant improvement in data collection, key biological processes and modeling approach has to be undertaken, which are the objectives of the ICCAT research program on ABFTE that started in 2010. This ambitious multi-annual program of $\sim 2$ million $€$ /year until 2013 includes five major actions: (i) a data recovery program, (ii) aerial surveys, (iii) a large-scale conventional tagging program (plus some electronic tagging), (iv) a biological program focusing on stock structure (through genetic and micro-chemistry), reproduction and ageing and $(v)$ population modeling studies. The program is ongoing and main results are expected by 2015. Besides the expected improvement in the quality/quantity of the catches data and age-length keys, the program should resolve (at least partly) the population structure and spatial dynamics of ABFTE and provide fisheries independent estimates of abundance and/or mortality rates.

The program also aims at developing modeling approaches that allow to account for observation errors and process errors, improve the modeling of key biological processes, include mixing between areas and use biologically realistic operating models for rigorous management strategy evaluation [MSE, see e.g. 35, 36]. MSE can also be used to guide the scientific process, i.e. to identify where the reduction of scientific uncertainties will primarily improve management and to ensure that expenditure is prioritized to provide the best research, monitoring and enforcement. MSE generally comprise an Operating Model (OM) that is used to simulate the main uncertainties about system 
dynamics and to test the performances of alternative management strategies. The development of MSE involves a number of steps [37]:

- Identification of management goals (and performance measures to quantify the extent to which those goals have been achieved).

- Selection of hypotheses that impact on the risk of not achieving those goals and development of OM representing those hypotheses.

- Conditioning of OM on available data and knowledge (and possible rejection of hypotheses, which are not compatible with those data and knowledge).

- Identification of candidate management strategies.

- Simulation of the performances of the management strategies by projecting the OM forward in which management is set using the management strategy.

- The evaluation of the management strategies based on the performances measured.

The MSE instigated by the CCSBT (Commission for the Conservation of Southern Bluefin Tuna) could help in defining such an approach for ABFT. This MSE has been initiated because divergent scientific views on the status and productivity of southern bluefin tuna as well as on appropriate management actions had resulted in no agreement on formal TAC for the majority of years between 1996 and 2004. This was due to uncertainty related to the underlying assumptions about spatial dynamics of the population and fishing fleets, the basic biology, appropriate assessment methods and appropriate approaches for resolving the major uncertainties for the provision of management advice $[38,39]$.

Uncertainties in the ABFTE stock assessment are relatively well-identified and albeit substantial efforts have recently been undertaken to improve scientific advice, several challenges remain. One of the biggest is the difficulty in accounting for uncertainties that are not due to the lack of current 
knowledge, but to stochastic processes. Since Hjort [40, 41]'s pioneering works, the recruitment dynamics and the early stages natural mortality of bony fish are known to be highly variable from year-to-year because of the match/mismatch in the time and space of fish larval production and favorable abiotic (e.g. temperature and currents) and biotic (prey and predators) conditions [42]. A recent study on ABFTE has confirmed the high variability of natural mortality rates during the first six months of life [ $M$ ranging between $7.7 y-1$ and $21.9 y$-1, i.e. between 1/2.500 and 1/3.3 billion surviving individuals, 43]. Such stochastic processes thus impose scientists to base their scientific advice on modeling approaches that are robust to such sources of uncertainties.

\section{Uncertainties in the management}

Management decisions do not rely solely on scientific advice. Indeed the Precautionary Approach allows for a consideration of social and economic factors [44]. The recent history of ABFTE showed that decisions mostly come from power relations between economic and conservation objectives. Fisheries interests were most influential at maintaining fishing rights and high catch levels until 2006. Using the argument of uncertainty in the scientific advice, they pushed managers to obtain higher TAC than the scientific advice and avoided a reduction in effort. As described above, this situation led to a severe overexploitation of ABFTE and to a risk of fisheries and stock collapse [9]. During the 2006-2011 years, the environmental NGOs became more powerful and used communication tools with the general public very efficiently to call attention to the poor stock status of ABFTE. To do so, NGOs (because they are not scientific bodies) sometimes used dramatic (and scientifically incorrect) terminology to describe ABFT status, such as "extinction", "Race for the last bluefin" [1] and could also be selective in communicating the scientific advice. Although such a strategy can undermine science-based management in the long-term, it was finally beneficial for ABFTE management and probably saved the ABFTE fisheries and stock from collapse. It indeed raised public awareness of ABFTE stock status and, in turn, obliged ICCAT to really pay attention to the scientific advice. When 
the first signs of ABFTE rebuilding were mentioned [28], some NGOs (not all) had the same strategy as the fisheries lobbies in the past and discredited the scientific advice by exploiting the various sources of uncertainty to get more conservative management measures. The risk to the stock is nonetheless not symmetric, as it is rational to advocate for low catches when there is high uncertainty in the scientific advice [34]. Nowadays, all the NGOs have recognized the beginning of ABFTE rebuilding and the relations between economic interests and the sustainable use of resources appears quite balanced, but pressure to increase TAC is becoming heavier as the population rebuilds. So, the possibility that ICCAT commission goes back to its old practices and decides, in the coming years, higher TAC than scientifically recommended is not negligible and it is therefore necessary to set future TACs on a more objective basis [as mentioned above, see also 45, 46, 47].

Questioning the scientific advice through the issue of uncertainty has thus been commonly used by different lobbies that wished to push their own agendas. Uncertainty is also a source of misunderstanding between scientists and managers for whom uncertainty often means poor advice. However, uncertainty is inherent in the scientific advice. Like in all fields of science, fisheries scientists cannot provide certainties, but only probabilities and sometimes consensus. In some cases, those probabilities can be seriously biased because of unquantified uncertainties. As described above, some sources of uncertainties in the ABFTE stock assessment can be reduced in improving scientific knowledge and models, but stochastic uncertainty (i.e. variability in the population dynamics caused by intrinsic variations in biotic and abiotic factors) will remain. It is up to fisheries scientists to actively communicate with managers, stakeholders and NGOs about the various sources of uncertainty, firstly to better inform about the scientific process and then to investigate alternative management strategies. It is also crucial to identify those unquantified uncertainties and to evaluate their impact on the outcomes of the assessment [i.e. how different the true risk might be, 48]. Such an approach is not trivial and implies to agree upon which of the unqualified uncertainties should be included in the evaluations. Some authors [see 37] suggested that scientists and stakeholders debate a limited number of scenarios, which can be first identified in a qualitative way, as being areas of 
concern. These scenarios can be then refined to be addressed quantitatively. This will allow key scenarios to be considered along with variants, likely ranges for parameters and relative weighting of different scenarios.

The current stock assessment procedure is designed to achieve long-term objectives, such as the maximum sustainable yield with low risk of stock collapse. However, decision-makers have to balance long-term conservation objectives with short-term economic and social objectives and are often pushed to produce quick results. This has led to, among other things, the stock assessment being performed every two years, which makes little sense for a long-lived species. Since the impact of management measures, such as minimum size or TAC established to reach MSY need time to be observed, as it takes time for the individuals and the populations to grow. This is also counterproductive, as scientists then have to spend most of their time to replicate the same analyses instead of working at the reduction of the uncertainties by investigating new and more robust approaches and improving data collection and knowledge. The robustness of the assumptions made in those assessments has seldom been evaluated and indicators from the fishery may contradict the assessment, discrediting it in the eyes of other parties. This means that for long-lived species, longterm management plans must be planned and agreed. Likewise, management decisions (when they appear to be successful) should be kept constant until the recovery is achieved. The development of MSE would help to do so and would further add stability to the management process (including TAC decision process), as management objectives (and how to evaluate how well alternative management actions meet them) are agreed through a dialogue between scientists, managers and stakeholders $[49,50]$.

\section{Conclusion}

The recent history of ABFTE management demonstrated that improving stock status of a heavily overexploited and valuable stock can be achieved when there is the political will. Neither the high economic value, nor the uncertainties in the scientific advice impaired management. Long-term 
sustainable exploitation is possible without any scientific advice, as shown by the history of many small scale fisheries that were based on community-oriented systems of territorial behavior [see e.g. 51]. However, optimizing long-term yields of modern fisheries operating in International waters probably implies good science. Scientific monitoring and research necessitates a continuous and substantial amount of money, which most of the national or international programs could not guarantee. To face such a common limitation, the implementation of a scientific quota for ABFT (and for many other exploited fish species) could be a way forward. This quota could be part of management plans of the exploited fish species to carry out any relevant studies related to the scientific advice, i.e. from the monitoring of the fisheries and fish populations to the modeling. More science, less uncertainty and better management recommendations should finally translate into lower risks of fisheries and population collapse, mid- and long-term sustainable management and finally increased revenues of the fisheries. 


\section{References}

[1] WWF. Race for the last bluefin. Zurich: WWF Mediterranean; 2008. 126pp.

[2] Garcia S, Grainger JR. Gloom and doom? The future of marine capture fisheries. Philosophical Transactions of the Royal Society, Serie B. 2005;360:21-46.

[3] Hilborn R. Managing fisheries is managing people: what has been learned? Fish and Fisheries. 2007;8:285-96.

[4] Pauly D, Christensen V, Guénette S, Pitcher TJ, Sumaila UR, Walters CJ, et al. Towards sustainability in world fisheries. Nature. 2002;418:689-95.

[5] Fromentin J-M, Powers JE. Atlantic bluefin tuna: population dynamics, ecology, fisheries and management. Fish and Fisheries. 2005;6:281-306.

[6] Fromentin J-M, Ravier C. The East Atlantic and Mediterranean bluefin tuna stock: looking for sustainability in a context of large uncertainties and strong political pressures. Bulletin of Marine Science. 2005;76:353-62.

[7] ICCAT. 1998 SCRS detailed report on bluefin tuna. Collective Volume of Scientific Papers ICCAT. 1999;49:1-191.

[8] Aps R, Kell LT, Lassen H, Liiv I. Negotiation framework for Baltic fisheries management: striking the balance of interest. ICES Journal of Marine Science. 2007;64.

[9] ICCAT. Report of the 2006 Atlantic Bluefin Tuna Stock Assessment Session. Collective Volume of Scientific Papers ICCAT. 2007;60(3):652-880.

[10] ICCAT. Report of the 2008 Atlantic Bluefin Tuna Stock Assessment Session. Collective Volume of Scientific Papers ICCAT. 2009;64:1-352.

[11] Fromentin J-M. The fate of Atlantic tuna. Science. 2010;327:1325-6.

[12] Fromentin J-M. The Status of Atlantic tuna (response). Science. 2010;328:1353-4.

[13] Losada S, Lieberman S, Drews C, Hirshfield M. The Status of Atlantic tuna. Science. 2010;328:1353-4. 
[14] ICCAT. Report of the 2012 Atlantic Bluefin Tuna Stock Assessment Session. Collective Volume of Scientific Papers ICCAT. 2013; 69(1):1-198.

[15] Fromentin J-M, Bonhommeau S, Brisset B. Update of the index of abundance of juvenile bluefin tuna in the western Mediterranean Sea until 2011. Collective Volume of Scientific Papers ICCAT. 2013;69(1):454-462.

[16] Fromentin J-M. Lessons from the past: investigating historical data from bluefin tuna fisheries. Fish and Fisheries. 2009;10:197-216.

[17] Cotter AJR, Burt L, Paxton CGM, Fernandez C, Buckland ST, Pan J-X. Are stock assessment methods too complicated? Fish and Fisheries. 2004;5:235-54.

[18] Begg GA, Friedland KD, Pearce JB. Stock identification and its role in stock assessment and fisheries management: an overview. Fisheries Research. 1999;43:1-8.

[19] Reiss H, Hoarau G, Dickey-Collas M, Wolff WJ. Genetic population structure of marine fish: mismatch between biological and fisheries management units. Fish and Fisheries. 2009;10:36195.

[20] Hauser L, Carvalho GR. Paradigm shifts in marine fisheries genetics: ugly hypotheses slain by beautiful facts. Fish and Fisheries. 2008;9:333-62.

[21] Carlsson J, McDowell JR, Diaz-Jaimes P, Carlsson JEL, Boles SB, Gold JR, et al. Microsatellite and mitochondrial DNA analyses of Atlantic bluefin tuna (Thunnus thynnus thynnus) population structure in the Mediterranean Sea. Molecular Ecology. 2004;13:3345-56.

[22] Riccioni G, Landi M, Ferrara G, Milano I, Cariani A, Zane L, et al. Spatio-temporal population structuring and genetic diversity retention in depleted Atlantic Bluefin tuna of the Mediterranean Sea. Proceedings of the National Academy of Sciences. 2010;107:2102-7.

[23] Viñas J, Pérez-Serra A, Vidal O, Alvarado Bremer JR, Pla C. Genetic differentiation between eastern and western Mediterranean swordfish revealed by phylogeographic analysis of the mitochondrial DNA control region. ICES Journal of Marine Science: Journal du Conseil. 2010;67:1222-9. 
[24] Schindler DE, Hilborn R, Chasco B, Boatright CP, Quinn TP, Rogers LA, et al. Population diversity and the portfolio effect in an exploited species. Nature. 2010;465:609-12.

[25] Gislason H, Daan N, Rice J, Pope J. Size, growth, temperature and the natural mortality of marine fish. Fish and Fisheries. 2010;11:149-58.

[26] Fromentin J-M. Bluefin Tuna stock assessment in the Northeast Atlantic. Problems related to data, methods and knownledge. Collective Volume of Scientific Papers ICCAT. 1999;49(2):38899.

[27] ICCAT. Report of the 2004 data exploratory meeting for the East Atlantic and Mediterranean bluefin tuna. Collective Volume of Scientific Papers ICCAT. 2005;58:662-99.

[28] ICCAT. Report of the 2010 Atlantic Bluefin Tuna Stock Assessment Session. Collective Volume of Scientific Papers ICCAT. 2011;66:505-714.

[29] Punt AE. A note on the modelling of MSY-related parameters when population dynamics are stochastic. Journal of Cetacean Research and Management. 2008;10:183-9.

[30] Porch CE. VPA-2BOX Version 3.01 User's guide. Miami, USA: National Marine Fisheries Service; 2003. $171 \mathrm{pp}$.

[31] Brooks EN, Powers JE, Cortés E. Analytical reference points for age-structured models: application to data-poor fisheries. ICES Journal of Marine Science. 2010;67:165-75.

[32] Patterson K, Cook R, Darby C, Gavaris S, Kell L, Lewy P, et al. Estimating uncertainty in fish stock assessment and forecasting. Fish and Fisheries. 2001;2:125-57.

[33] Kell LT, De Bruyn P, Mosqueira I, Magnusson A. An evaluation of the performance of the Kobé stratégy matrix: an example based upon a biomass assessment model. Collective Volume of Scientific Papers ICCAT. 2012;68:1018-29.

[34] Mäntyniemi S, Kuikka S, Rahikainen M, Kell LT, Kaitala V. The value of information in fisheries management: North Sea herring as an example. ICES Journal of Marine Science. 2009;66:227883. 
[35] Butterworth DS. Why a management procedure approach? Some positives and negatives. ICES Journal of Marine Science: Journal du Conseil. 2007;64:613-7.

[36] Kell LT, Die D, Restrepo V, Fromentin J-M, Ortiz de Zarate V, Pallares P. An evaluation of management strategies for Atlantic tuna stocks. Scientia Marina. 2003;67:353-70.

[37] Punt AE, Donovan GP. Developing management procedures that are robust to uncertainty: lessons from the International Whaling Commission. ICES Journal of Marine Science: Journal du Conseil. 2007;64:603-12.

[38] Kolody D, Polacheck T, Basson M, Davies CA. Salvaged pearls: lessons learned from a floundering attempt to develop a management procedure for Southern Bluefin Tuna Fisheries Research. 2008;94:339-50.

[39] Kurota H, Hiramatsu K, Takahashi N, Shono H, Itoh T, Tsuji S. Developing a management procedure robust to uncertainty for southern bluefin tuna: a somewhat frustrating struggle to bridge the gap between ideals and reality. Population Ecology. 2010;52:359-72.

[40] Hjort J. Fluctuations in the great fisheries of northern Europe. Viewed in the light of biological research. Rapports et Procès-verbaux des Réunions. Conseil International pour l'Exploration de la Mer. 1914;20:1-228.

[41] Hjort J. Fluctuations in the year classes of important food fishes. Journal du Conseil International pour l'Exploration de la Mer. 1926;1:5-38.

[42] Cushing DH. Plankton production and year class strength in fish populations: an update of the match/mismatch hypothesis. Advances in Marine Biology. 1990;26:249-93.

[43] Simon M, Fromentin J-M, Bonhommeau S, Gaertner D, Brodziak J, Etienne M-P. Effects of Stochasticity in Early Life History on Steepness and Population Growth Rate Estimates: An Illustration on Atlantic Bluefin Tuna. PLoS ONE. 2012;7:e48583.

[44] Kirkwood GP, Smith ADM. Assessing the precautionnary nature of fishery management strategies. FAO Fisheries Technical Papers. Rome1995. p. 141-58. 
[45] Kell LT, Pastoors MA, Scott RD, Smith MT, Van Beek FA, O'Brien CM, et al. Evaluation of multiple management objectives for Northeast Atlantic flatfish stocks: sustainability vs. stability of yield. ICES Journal of Marine Science. 2005;62:1104-17.

[46] Froese R, Branch TA, Proelß A, Quaas M, Sainsbury K, Zimmermann C. Generic harvest control rules for European fisheries. Fish and Fisheries. 2011;12:340-351.

[47] de Bruyn P, Murua H, Aranda M. The Precautionary approach to fisheries management: How this is taken into account by Tuna regional fisheries management organisations (RFMOs). Marine Policy. 2013;38:397-406.

[48] EFSA. Guidance on the environmental risk assessment of genetically modified animals. EFSA Journal. 2013;11:3200.

[49] Martin TG, Burgman MA, Fidler F, Kuhnert PM, Low-Choy S, McBride M, et al. Eliciting expert knowledge in conservation science. Conservation Biology. 2012;26:29-38.

[50] Röckmann C, Ulrich C, Dreyer M, Bell E, Borodzicz E, Haapasaari P, et al. The added value of participatory modelling in fisheries management - what has been learnt? Marine Policy. 2012;36:1072-85.

[51] Akimichi T. Territorial regulation in small-scale fisheries of Itoman, Okinawa. In: Ruddle $\mathrm{K}$ Akimichi T, editors. Maritime institutions in the Western Pacific: Senri Ethnological Studies. 1984;17:89-120. 


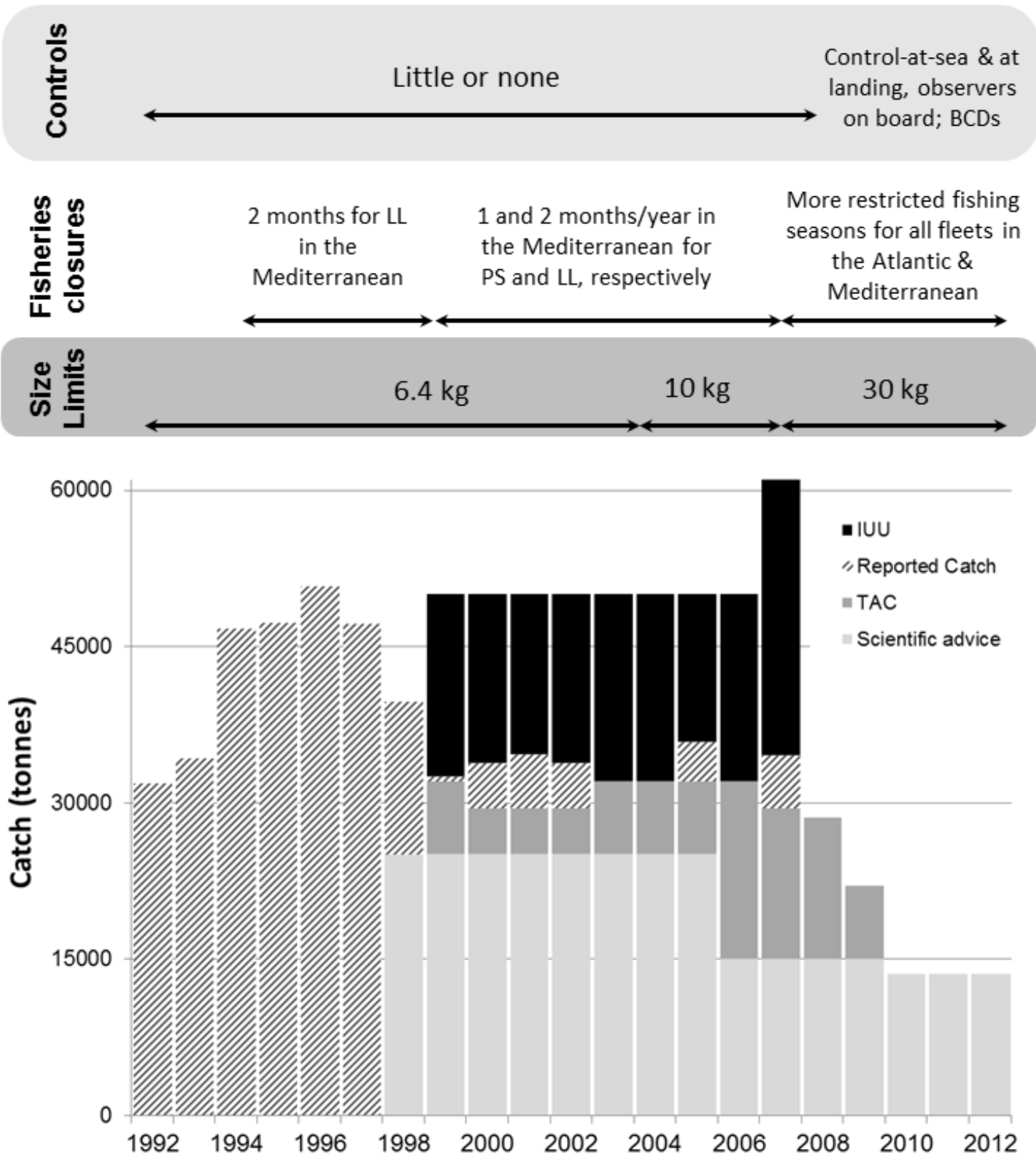

Figure 1. Catches levels recommended by ICCAT Scientific Committee (scientific advice), Total Allowable Catches (TAC) decided by ICCAT commission, reported catches to ICCAT secretariat and the Illegal-unreported-unregulated catches estimated by ICCAT Scientific Committee (IUU) from 1992 to 2012. Main management regulations over the same period are also described. 

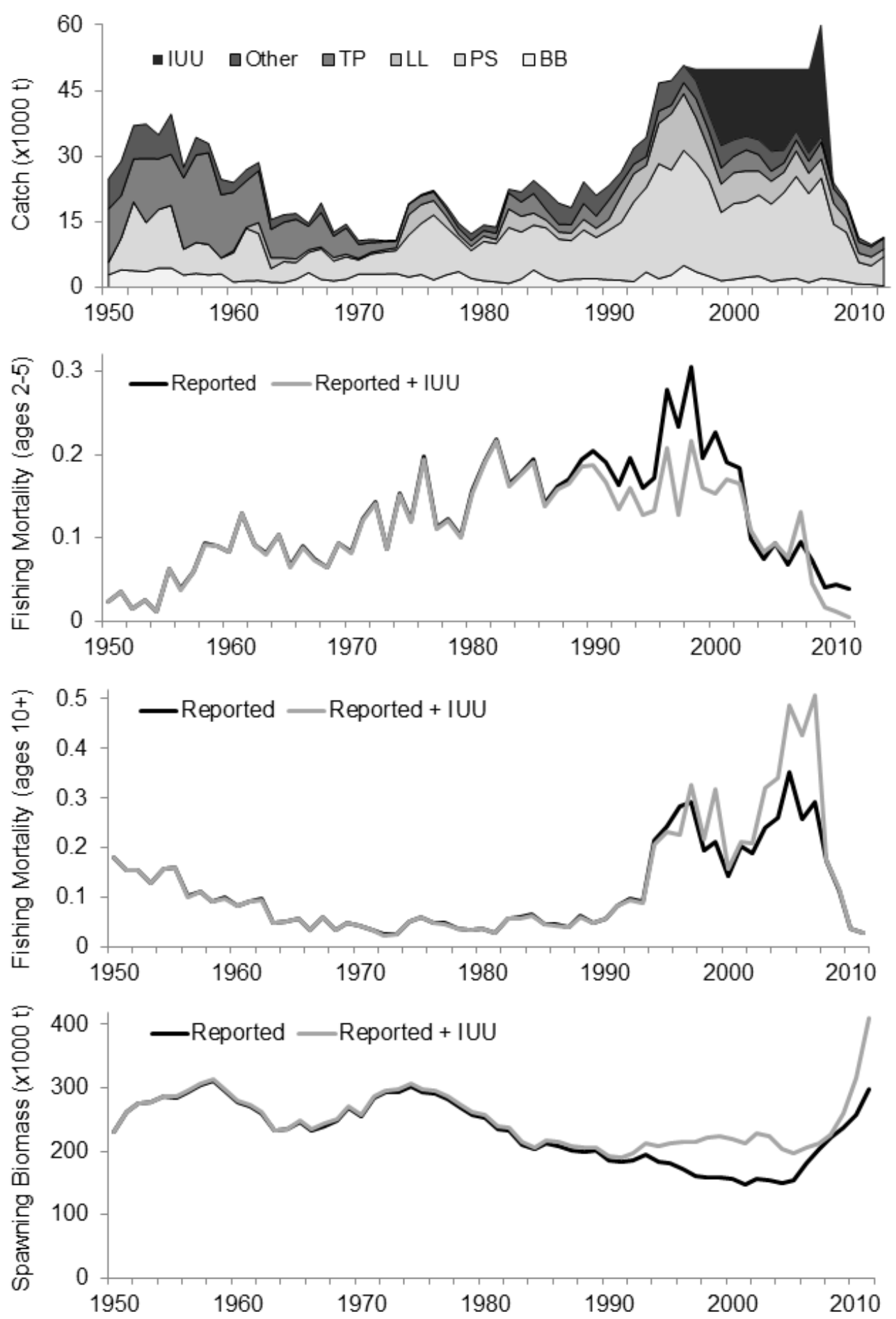

Figure 2. From top to bottom: Fishing mortality for ages 2 to 5 , fishing mortality for ages $10+$ and spawning stock biomass (in thousands of tons) estimates from the 2012 stock assessment performed by ICCAT Scientific Committee. Dark line: reported catch; Light grey line: reported plus estimated IUU catches (from 1998 to 2007). 